\title{
Letter to Editor - A Clinical 'PIC- Perspectives, issues \& Concerns" on Idiopathic Transient Osteoporosis during Pregnancy with alarm bells on its Idiopathic nature - Response
}

\author{
Prof. Dr. Sharat Agarwal ${ }^{1}$
}

Dear Editor,

At the outset, I would like to congratulate the authors of the article published in your journal in the current issue entitled- Idiopathic Transient Osteoporosis during Pregnancy - Report of a Clinical Case JOCR November-December 2019 Volume 9 Issue 6 Page 5457. However, I regret to mention that the workup mentioned in this article needs to be improved, before one can come to definitive diagnosis of Idiopathic Transient Osteoporosis during Pregnancy. I would like to highlight various perspectives, issues \& concerns, the knowledge of which are must for the readers of this journal pertaining to this disorder.

It is pertinent to mention no doubt the increasing utilization of magnetic resonance imaging (MRI) has allowed physicians to investigate edematous changes in bone marrow, a clinically important entity which was previously undetected on conventional radiographs. The first use of the term "bone marrow edema" was by Wilson et al in 1988, and the term "bone marrow edema syndrome" was described in 1993 after the investigation of histological specimens [1]. Later on, importantly Hayes et al. advocated that the term "transient bone marrow edema syndrome" should be used for patients in whom the bone marrow edema pattern was not accompanied by radiographic evidence of osteopenia [2]. And thus separating the two entities i.e. "the transient bone marrow edema syndrome" and "Transient Osteoporosis"

Occurrence of hip pain during pregnancy is quite common, although transient osteoporosis as a condition causing this symptom is uncommonly seen. Clinicians should also be aware of intra-articular disorders such as loose bodies, and labral tears; peri-articular pathology such as tendinitis and bursitis; or extra-articular conditions such as referred pain from the lumbar spine, the sacroiliac joint, and or from nerve entrapment syndromes. So, a detailed history and physical examination is helpful to narrow the differential diagnoses, which, in turn, dictate the modality of imaging studies \& other investigations to diagnose and/or confirm the diagnosis [3]. A special reference is to be made for the reasons of common musculoskeletal pains occurring in pregnancy such as osteoarthritis, avascular bone necrosis, lysis of symphysis pubis, fibromyalgia, rheumatic arthropathies, and finally tumor and pseudotumoral pathologies [4]. Including other pathologies like inflammatory arthritis of the hip, AVN, stress fracture of the femoral neck, synovial disorders and neoplasia [5].

The suggested etiologies for this condition include pelvic nerve compression, vascular insufficiency, or changes in fibrinolytic system with pregnancy although a definite cause remains unknown to this date [6]. However, the understanding of the underlining mechanisms requires prospective randomized trials (RCTs) or at least case-controlled studies, which can also be the research recommendation massage from this article. The strongest theory suggested is that a venous obstruction may play an essential role in TOH [7-9]. Koo et al suggested that coagulopathic factors result in an intraosseous ischemic event, affecting the veins and venous sinusoids of the hip [9]. Considering this, literature review suggests Coagulation profile to be included in the investigations while evaluating this disorder [10].

While the elevations of Homocysteine ( $>20 \mu \mathrm{mol} / \mathrm{L}$ for men and $>18 \mu \mathrm{mol} / \mathrm{L}$ for woman) confer a sizeable risk increase for bone fracture (4.1-fold men, 1.9-fold for women) [11] as has also been seen by association between Homocysteine levels and the risk of fracture primarily due to reduced mineral density [12]. So, the assessment of serum homocysteine levels is also crucial. Folate and Vitamin B12 level assessment is important as the defiencies have been found to be linked to osteoporosis [13].

Clinicians should remember that, bone mineral density (BMD) measured by DXA is low at the hip, while BMD at the lumbar spine may be low but substantially higher compared to hip BMD [14]. Also, several reports have suggested the relationship between TOH and low bone mineral density. Because bone mineral density changes with time in TOH [15], single-point measurement may cause the normal finding of bone mineral density, therefore repeated DXA may be required with strong suspicion of this condition.

This should be followed by image-guided hip aspiration especially where imaging reveals hip joint effusion as it is important to rule out

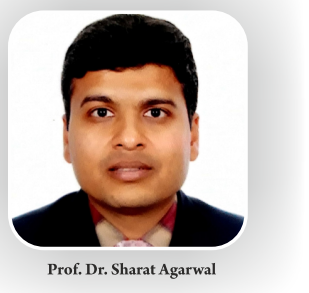

${ }^{1}$ Department of Orthopaedics \& Trauma, North Eastern Indira Gandhi Regional Institute of Health \& Medical Sciences (NEIGRIHMS), Shillong (India).

Address of Correspondence:

Prof. Dr. Sharat Agarwal,

Department of Orthopaedics \& Trauma, North Eastern Indira Gandhi Regional Institute of Health \& Medical Sciences

(NEIGRIHMS), Shillong (India)

Email-drsharat88@yahoo.com

Journal of Orthopaedic Case Reports | pISSN 2250-0685 | eISSN 2321-3817 | Available on www.jocr.co.in | doi:10.13107/jocr.2021.v11.i01.1990 This is an Open Access article distributed under the terms of the Creative Commons Attribution Non-Commercial License (http://creativecommons.org/licenses/by-nc/3.0) which permits unrestricted non-commercial use, distribution, and reproduction in any medium, provided the original work is properly cited. 
negative for Gram stain and growth of organisms. More so, as mentioned in the article the diagnosis of transient osteoporosis is diagnosis of exclusion.

There is also a need to inform the readers, that with inflammatory arthropathies of the hip, plain radiographs show that the pattern of joint space loss is predominantly axial in contrast to the superior joint loss typical of osteoarthritis.

Also, in patients with septic arthritis, MRI may depict associated marrow edema and suggest its reactive or infectious origin. For the neoplasms, although plain radiographs should be the initial examination, MRI may follow for assessing extension to the surrounding soft tissues and/or associated pathologic fracture, facilitating the treatment planning [16]. As mentioned, MRI is the investigation of choice to exclude other diagnoses. It is very important to be thorough with the findings of MRI in TOH, which shows decreased signal intensity of bone marrow on T1-images and increased signal intensity relative to the intensity of normal marrow on T2-images. Joint effusions are seen on T2-images. An absence of subchondral lesions, delayed peak enhancement of the abnormal marrow on perfusion images and sparing of the subchondral zone from marrow oedema are MRI findings highly correlated to TOH [17]. The absence of focal changes on MRI is highly suggestive of a transient lesion [18]. A special attention should be made to avoid confusing this condition with avascular necrosis of hip as these findings may be confused with avascular necrosis of the femoral head or femoral neck stress fracture $[19,20]$. However, diffuse rather than focal involvement of the femoral head or neck helps differentiate these entities from TOH [21]. Also, MRI can detect possible subchondral fractures, while the absence of subchondral changes on contrasted sequences is crucial for the diagnosis

So, in absence of addresal of the key issues mentioned above especially without including testing of coagulation profile, serum homocysteine levels, ruling out folate \& Vitamin B12 deficiency, joint aspiration and testing for organisms and issues related to MRI as mentioned here there is serious concern on labelling TOH in this article as "Idiopathic".

A mention should be made about the use of antiresorptive agents, including calcitonin and bisphosphonates, which have been reported to alleviate pain and accelerate clinical and radiological recovery, although these data come from individual case reports and uncontrolled case series [22]. Good efficacy has been found with the use of intraarticular steroid injection to give symptomatic relief. Even prostaglandins, prednisolone, and the bone-sparing steroid, as well as deflazacort have also been used [23].

Khastgir et al. also believed that pregnancy is the precipitant, rather than the cause, of osteoporosis [24]. That is to say, the pregnant woman who are having osteopenia prior to pregnancy, should be identified and followed up especially with likelihood of this particular bone weakening disorder, so that the relatively serious complication of occurrence of peripartum hip fracture can be avoided. Recovery time is said to be anywhere from 2 to 12 months, though lactation may prolong the process [25], which may require a close watch and prolonged use of calcium and vitamin D supplementation.

References:

1. Wilson AJ, Murphy WA, Hardy DC, Totty WG Transient osteoporosis or transient bone marrow edema? Radiology. 1988; 167(3): 757-760. doi:10.1148/radiology.167.3.3363136.

2. C. W. Hayes, W. F. Conway, and W. W. Daniel, "MR imaging of bone marrow edema pattern: transient osteoporosis, transient bone marrow edema syndrome, or osteonecrosis," Radiographics, vol. 13, no. 5, pp. 1001-1012, 1993.

3. Jude CM, Modarresi S. Radiologic evaluation of the painful hip in adults. 2011. $\mathrm{http} / / / \mathrm{www}$.uptodate.com/contents/radiologic-evaluation-of-the-painful-hip-in-adults

4. Willis-Owen CA, Daurka JS, Chen A, Lewis A. Bilateral femoral neck fractures due to transient osteoporosis of pregnancy: A case report. Cases J 2008;21:1-120.

5. Ma FY, Falkenberg M. Case reports: transientos-teoporosis of the hip: an atypical case. Clin Orthop Relat Res. 2006 Apr;445:245-9.

6. Lose G, Lindholm P. Transient painful osteoporosis of the hip in pregnancy. Int J Gynaecol Obstet. 1986 Feb;24(1):13-16.

7. Rosen RA Transitory demineralization of the femoral head. Radiology. 1970; 94:509-512. doi:10.1148/94.3.509

8. Plenk PH Jr, Hofmann S, Eschberger J, et al. Histomorphology and bone morphometry of the bone marrow edema syndrome of the hip. Clin Orthop Relat Res. 1997; 334:73-84.

9. Koo KH, Jeong ST, Jones JP Borderline necrosis of the femoral head. Clin Orthop Relat Res. 1999; 358:158-165. doi:10.1097/00003086-199901000-00019

10. Aref A. Bin Abdulhak, Fawziah A. Ba-Mougadam, Nizar A. Al-Nakshabandi,and Mohamad A. Al-Tannir. Transient Osteoporosis of the Hip/Bone Marrow Edema Syndrome with Soft Tissue Involvement: A Case Report Oman Med J. 2011 Sep; 26(5): 353-355. doi: 10.5001/omj.2011.86 
11. McLean RR, Jacques PF, Selhub J, Tucker KL, Samelson EJ, Broe KE, et al. Homocysteine as a predictive factor for hip fracture in older persons. N Engl J Med. (2004) 350:2042-9. doi: 10.1056/NEJMoa032739

12. van Meurs JBJ, Dhonukshe-Rutten RAM, Pluijm SMF, van der Klift M, de Jonge R, Lindemans J, et al. Homocysteine levels and the risk of osteoporotic fracture. N Engl J Med. (2004) 350:2033-41. doi: 10.1056/NEJMoa032546

13. Patricia McWalter and Ahmed Hassan Transient osteoporosis of the hip Ann Saudi Med. 2009 Mar-Apr; 29(2): 146-148. doi: 10.4103/0256-4947.51801

14. Anai T, Urata K, Mori A, Miyazaki F, Okamoto S (2013) Transient osteoporosis of the hip in pregnancy associated with generalizedlow bone mineral density—a case report. Gynecol Obstet Investig. 76(2):133-138

15. R. Niimi, A. Sudo, M. Hasegawa, A. Fukuda, and A. Uchida. "Changes in bone mineral density in transient osteoporosis of the hip.” The Journal of Bone\& Joint Surgery (British Volume), vol. 88, no. 11, pp. 1438-1440, 2006.

16. Karantanus AH. Acute bone marrow edema of the hip: role of MR imaging. Eur Radiol. 2007 Sep;17(9):2225-36

17. Malizos KN, Zibis AH, Dailiana Z, Hantes M, Karachalios AH. MR imaging findings in transient osteoporosis of the hip. Eur J Radiol. 2004 Jun;50(3):238-44.

18. Balakrishnan A, Schemitsch EH, Pearce D, McKee MD. Distinguishing transient osteoporosis of the hip from avascular necrosis. Can J Surg. 2003 Jun;46(3):187-92

19. Becker CB, Cohen A. Epidemiology and etiology of premenopausal osteoporosis. UpToDate. Last updated August 4, 2011. Last date of access: November 19, 2011. http://www.uptodate.com/contents/epidemiologyand-etiology-of-premenopausal-osteoporosis

20. DukeOrthopaedics. http://www.wheelessonline.com/ortho/idiopathic transient_osteoporosis of the hip 2012.

21. Jude CM, Modarresi S. Radiologic evaluation of the painful hip in adults. UptoDate 2011. http://www.uptodate.com/contents/radiologic-evaluation-of-the-painful-hip-in-adults

22. Bolland MJ. Bilateral transient osteoporosis of the hip in a young man. J Clin Densitom. 2008 Apr;11(2):339-341.

23. La Montagna G, Malesci D, Tirri R, Valentini G. Successful neridronate therapy in transient osteoporosis of the hip. Clin Rheumatol 2005. Feb;24(1):67-69

24. Khastgir G, Studd J. Pregnancy-associated osteoporosis. Br ] Obstet Gynaecol. 1994;101:836-838.

25. Sowers M. Pregnancy and lactation as risk factors for subsequent bone loss and osteoporosis. ] Bone Miner Res. 1996;11:1052-1060.

How to Cite this Article
Agarwal S. Letter to Editor - A Clinical 'PIC- Perspectives, issues \&
Concerns" on Idiopathic Transient Osteoporosis during Pregnancy with
alarm bells on its Idiopathic nature-Respons. Journal of Orthopaedic Case
Reports 2021 January;11(1):118-120.

